ARTICLE

\title{
Stereospecific Si-C coupling and remote control of axial chirality by enantioselective palladium- catalyzed hydrosilylation of maleimides
}

\author{
Xing-Wei Gu (1) 1, Yu-Li Sun (10) 1, Jia-Le Xie (1) 1, Xing-Ben Wang (10) 1, Zheng Xu (1) 1, Guan-Wu Yin (1) 1, Li Li (1) 1, \\ Ke-Fang Yang (iD ${ }^{1} \&$ Li-Wen Xu (i) ${ }^{1,2 \otimes}$
}

Hydrosilylation of unsaturated carbon-carbon bonds with hydrosilanes is a very important process to access organosilicon compounds and ranks as one of the most fundamental reactions in organic chemistry. However, catalytic asymmetric hydrosilylation of activated alkenes and internal alkenes has proven elusive, due to competing reduction of carboncarbon double bond or isomerization processes. Herein, we report a highly enantioselective $\mathrm{Si}-\mathrm{C}$ coupling by hydrosilylation of carbonyl-activated alkenes using a palladium catalyst with a chiral TADDOL-derived phosphoramidite ligand, which inhibits O-hydrosilylation/olefin reduction. The stereospecific $\mathrm{Si}-\mathrm{C}$ coupling/hydrosilylation of maleimides affords a series of silyl succinimides with up to $99 \%$ yield, $>99: 1$ diastereoselectivity and $>99: 1$ enantioselectivity. The high degree of stereoselectivity exerts remote control of axial chirality, leading to functionalized, axially chiral succinimides which are versatile building blocks. The product utility is highlighted by the enantioselective construction of $\mathrm{N}$-heterocycles bearing up to three stereocenters.

\footnotetext{
${ }^{1}$ Key Laboratory of Organosilicon Chemistry and Material Technology of Ministry of Education, and Key Laboratory of Organosilicon Material Technology of Zhejiang Province, Hangzhou Normal University, No. 2318, Yuhangtang Road, Hangzhou 311121, PR China. ${ }^{2}$ State Key Laboratory for Oxo Synthesis and Selective Oxidation, Suzhou Research Institute (SRI) and Lanzhou Institute of Chemical Physics (LICP), University of Chinese Academy of Sciences (UCAS), Lanzhou 730000, PR China. ${ }^{\bowtie}$ email: liwenxu@hznu.edu.cn
} 
S ilicon-carbon bond-forming reactions, including $\mathrm{C}-\mathrm{H} / \mathrm{C}-\mathrm{X}$ silylation, hydrosilylation, and cross-exchange of $\mathrm{Si}-\mathrm{C}$ bond, have been considered as the key topic and cornerstone of organosilicon chemistry and of great value in organic synthesis and functional materials ${ }^{1-7}$. However, the stereospecific construction of $\mathrm{Si}-\mathrm{C}$ bond remains challenging and underexploited, thereby preventing the enantioselective functionalisation of organosilicon compounds and downstream transformations. Here, we reported a highly enantioselective $\mathrm{Si}-\mathrm{C}$ coupling hydrosilylation of carbonyl-activated alkenes using palladium catalysis with chiral TADDOL-derived phosphoramidite ligand, which inhibited previously common O-hydrosilylation/reduction of carbon-carbon double bond. This was proved in the enantioselective hydrosilylation in maleimides as well as the remote control of axial chirality of $\mathrm{N}$-arylmaleimides via a single-step transformation. The products could be obtained in up to $99 \%$ yield, $>99: 1$ diastereomeric ratio (for axial chirality) and $>99: 1$ enantiomeric ratio. On the basis of experimental results, we elucidated the mechanistic details and the utility of the approach in synthetic chemistry and photocatalysis that was highlighted by the enantioselective construction of chiral $\mathrm{N}$-heterocycles bearing one to three carbon-stereogenic centres.

Notably, hydrosilylation of unsaturated carbon-carbon bonds with hydrosilanes ranks one of the most fundamental reactions in industrial chemical production ${ }^{8-14}$, such as the production of coupling silane and silicone rubber ${ }^{15}$. And recently it has become a very important process to access synthetically useful organosilicon compounds and chiral organosilanes ${ }^{16-18}$ that are useful in asymmetric catalysis, functional materials, and can be employed as silicon-containing drug candidates. However, chiral silanes with functional groups are still difficult to be constructed via $\mathrm{Si}-\mathrm{C}$ coupling due to the scarcity of highly enantioselective or broadly applicable methods. This limitation might discourage the pursuit of bioactive organosilicon compounds as drug candidates or chiral Si-based materials ${ }^{19-21}$, despite functionalized silanes are exceptionally important for industrial processes or modern material technology across a wide range of disciplines. To date, asymmetric hydrosilylation is one of the core $\mathrm{Si}-\mathrm{C}$ coupling transformations for the construction of chiral silanes. Very recently, several well-established protocols have been developed to the enantioselective hydrosilylation of terminal alkenes and alkynes for the synthesis of chiral organosilicon compounds with good regio- and enantioselectivities (Fig. 1a) ${ }^{22-29}$, which has been recognised as a hot topic in organic synthesis in the past years. In contrast, the enantioselective hydrosilylation of internal alkenes or its analogues are uncommon, and the synthetic capabilities for the catalytic asymmetric hydrosilylation of activated alkenes are also presently limited ${ }^{30,31}$. Catalytic asymmetric hydrosilylation of activated alkenes and internal alkenes have been proven elusive, because the reduction of carbon-carbon double bond or isomerization is much less energetically favourable. For example, the hydrosilylation of EWG-activated alkenes may generate mixtures of reductive product, $\alpha$ - and $\beta$-adducts, and especially for $\alpha, \beta$-unsaturated carbonyl compounds, silyl ketene acetals $(O-$ silylation adduct with 1,4-addition), silyl ethers/amines (O-silylation adduct with 1,2-addition), and polymeric byproducts were also obtained depending on the catalyst systems (Fig. 1b) ) $^{32-34}$. Although there have been much efforts made to achieve chemoor regio-selective hydrosilylation of $\alpha, \beta$-unsaturated carbonyl compounds, only a few examples of $\mathrm{Si}-\mathrm{C}$ coupling $\mathrm{C}$-silylation are known ${ }^{35-37}$, and no successful report has been published on the enantioselective $\mathrm{Si}-\mathrm{C}$ coupling hydrosilylation of $\alpha, \beta$-unsaturated carbonyl compounds, to the best of our knowledge.

Because of the abundance and potentially bioactivity of imide/ amide-containing nature products, maleimide and its derivatives are versatile building blocks for synthetic chemistry and functional a Classic catalytic asymmetric hydrosilylation and its inherent challenges

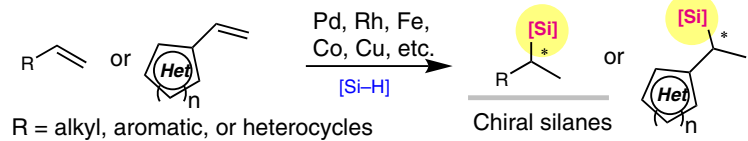

$\mathrm{R}=\mathrm{alkyl}$, aromatic, or heterocycles (commonly used)

$[\mathrm{Si}]=\mathrm{HSiCl}_{3}, \mathrm{ArSiH}_{2}, \mathrm{ArRSiH}$

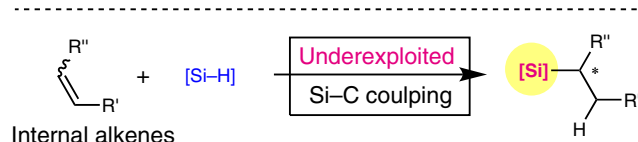

b

Possible pathways in catalytic hydrsoilyaltion of carbonyl-activated alkenes

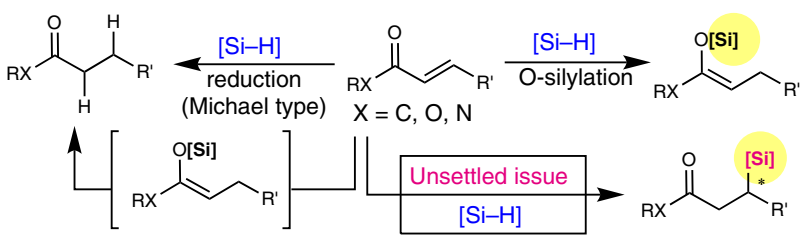

C The mechanistic analysis for the competitive hydrosilylation

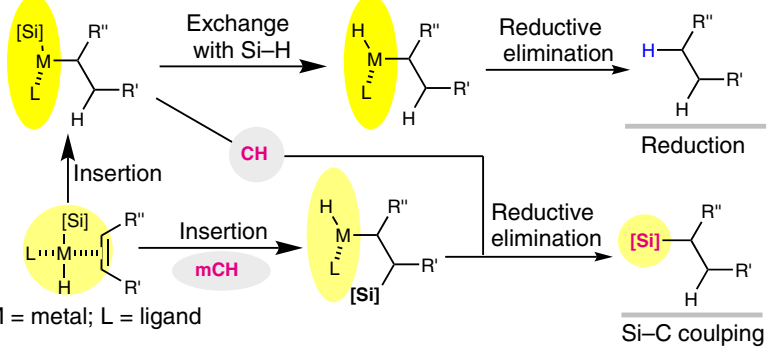

d



Si-C coupling hydrosilylation

Remote control of axial chirality

High enantioselectivity

Excellent chemoselectivity

Fig. 1 Chemo- and stereo-selective issues with hydrosilylation. a Catalytic asymmetric hydrosilylation of terminal alkenes mediated by transitionmetal catalysts. b Traditional methods for hydrosilylation of EWG-activated alkenes led to reduction and $\mathrm{O}$-silylation. c Two classic pathways for transition-metal-catalysed hydrosilylation of alkenes, and its mechanistic analysis should encourage greater adoption of $\mathrm{Si}-\mathrm{C}$ coupling methods for the hydrosilylation of internal alkenes. $\mathbf{d}$ The catalytic desymmetric hydrosilylation of $\mathrm{N}$-arylmaleimides for remote control of axial chirality. $\mathrm{CH}$ is Chalk-Harrod mechanism, and $\mathrm{mCH}$ is modified Chalk-Harrod mechanism.

materials ${ }^{38-41}$, allowing for subsequent transformations of skeletal variation and investigation as drug candidates ${ }^{42}$. However, in contrast to the hydrosilylation of general electron-rich alkenes/ alkynes, the synthetic power of hydrosilylation of electron-deficient alkenes, including maleimide, has not fully established ${ }^{43}, 44$ this stereoselectivity for $\mathrm{Si}-\mathrm{C}$ coupling silylation of $\alpha, \beta$-unsaturated carbonyl compounds has not been challenged. First, catalytic hydrosilylation of $\alpha, \beta$-unsaturated carbonyl compounds usually 
affords solely a conjugated reduction product, thus a catalyst system should be identified to overcome the expected reductive hydrosilylation. Second, the $\alpha, \beta$-unsaturated carbonyl compounds containing functional carbonyl group, the catalyst must be capable of good group tolerance as well as effective control of enantioselectivity. In addition, for more than 30 years, especially after Hayashi's milestone discovery that Pd-MOP complexes catalysed Markovnikov-type asymmetric hydrosilylation with trichlorosilane ${ }^{45}, 46$, the selectivity of palladium-catalysed $\mathrm{Si}-\mathrm{C}$ coupling hydrosilylation of $\alpha, \beta$-unsaturated carbonyl compounds has not been well established. Thus, this challenge motivates us to aim at developing an enantioselective hydrosilylation of maleimides, providing a straightforward approach to a wide range of silyl-functionalized carbonyl compounds that can enrich the chiral synthesis toolbox with distinct chemo- and stereoselelectivity. Based on the analysis of reaction mechanisms for metal-catalysed hydrosilylation and reduction with hydrosilanes revealing the potential migratory insertion and ligand-controlled hydride transfer (Fig. 1c), and inspired by previous reports on the role of secondary interactions in the asymmetric palladiumcatalysed hydrosilylation of olefins with chiral monophosphine ligands $s^{47}$, we envisioned that an appropriate ligand with a cavitylike structure could reverse the chemoselectivity from reduction to $\mathrm{Si}-\mathrm{C}$ coupling silylation and might control the enantioselectivity of hydrosilane addition to $\mathrm{C}=\mathrm{C}$ bond of maleimides. Therefore, if a chiral ligand bearing a bulky and cavity-like group as well as displaying suitable secondary interactions could be beneficial to the formation of a proton shuttle for subsequent Si-C coupling hydrosilylation, a highly enantioselective hydrosilylation of EWG-activated alkenes (EWG: electron-withdrawing group) would be achieved.

Herein, we report our recent efforts to establish a palladiumcatalysed protocol for the catalytic asymmetric hydrosilylation of maleimides with hydrosilanes to provide silylated carbon stereocenters, with high chemo- and enantioselectivity (Fig. 1d). Through the asymmetric palladium-catalysed hydrosilylation of $\mathrm{N}$-arylmaleimides, the remote control of axial chirality of atropisomeric succinimides could be achieved during the $\mathrm{Si}-\mathrm{C}$ coupling. The key feature of present methodology is the ability of the palladium catalyst to exert stereochemical induction from functionalisation of $\mathrm{C}-\mathrm{C}$ double bond to the formation of the remote $\mathrm{C}-\mathrm{N}$ axis ${ }^{48}, 49$ via a single $\mathrm{Si}-\mathrm{C}$ bond-forming process unlike previously reported Michael addition ${ }^{50-53}$ or well-established cycloaddition $^{54-57}$. Computational studies reveal the mechanism of the palladium-catalysed C-silylation and support the unusual stereoselectivity.

\section{Results}

Optimisation of reaction conditions. We first carried out a model hydrosilylation involving $N$-phenylmaleimide $\mathbf{1 a}$ and the commercially available diphenylmethylsilane $2 \mathrm{a}$ with chiral Pligand and $\mathrm{Pd}_{2}(\mathrm{dba})_{3} \cdot \mathrm{CHCl}_{3}$. Unfortunately, owing to competition of reduction and $\mathrm{Si}-\mathrm{C}$ coupling hydrosilylation, most of commercially available phosphine ligands, such as 2,2'-bis (diphenylphosphino)-1,1'-binaphthyl (BINAP), 2-(diphenylphosphino)-2'-methoxy-1,1'-binaphthyl (MOP), and other P-ligands resulted into reductive products but only with trace amount of desired products (Entries 14-18 of Table 1). And as expected, it was found that only chiral TADDOL-derived phosphoramidites bearing aromatic bulky groups could give low to moderate yields of desired silyl product $\mathbf{3 a}$ in the palladium-catalysed hydrosilylation of $N$-phenylmaleimide (Table 1 and Supplementary Table 1, TADDOL $=1,1,4,4$-tetra-aryl-2,3-O-isopropylidene-Lthreitol). In the event, at $60^{\circ} \mathrm{C}$ and after $18 \mathrm{~h}$ the conversion of $1 \mathrm{a}$ was completely and the desired product was obtained in $68 \%$ with
94\% ee in the presence of chiral TADDOL-derived phosphoramidite L12 (Entry 12 of Table 1). These experimental data showed the steric repulsion of chiral P-ligand inhibit the reductive $O$-hydrosilylation. However, small amounts of the side product (32\% 1-phenyl-pyrrolidine-2,5-dione) were still detected because of reductive hydrosilylation. The formation of reductive product implies that the pathway involving $\mathrm{Si}-\mathrm{C}$ coupling is accompanied by $\mathrm{Si}-\mathrm{H}$ activation and subsequent hydrogentransfer to Pd-Si bond (Fig. 1c). Under the same conditions but with other TADDOL-derived phosphoramidites resulted into decreased chemoselectivities (from 4:96 to 59:41 c.r.) and enantioselectivities (31-93\% ee, see entries 1-14 of Table 1). Next, we examined the effect of palladium catalyst precursors (Supplementary Table 2). In certain cases better chemoselectivity was generated with the same good enantioselectivity when $\mathrm{Pd}_{2}(\mathrm{dba})_{3}$ as Pd catalyst ( $85 \%$ yield of $3 a, 94 \% e e)$. Then after an extensive evaluation of solvents, reaction temperature, and phosphorous ligands, the $\mathrm{Pd}_{2}(\mathrm{dba})_{3} / \mathbf{L 1 2}$ was identified as an effective catalyst for the model hydrosilylation of $\mathrm{N}$-arylmaleimide in toluene at $50{ }^{\circ} \mathrm{C}$ (entry 20 of Table 1, for 3a, 93:7 c.r., 96\% ee). Notably, some of experimental data were unexpected, for example, higher temperature was beneficial to the $\mathrm{Si}-\mathrm{C}$ coupling hydrosilylation but not the reduction (Supplementary Table 4). However, the reaction performed at higher temperature was sacrificed in term of stereoselectivity to some extent.

Scope of the palladium-catalysed hydrosilylation of maleimides. We then evaluated a series of maleimides to probe the reaction scope to generate the synthetic information about the stereospecific Si-C coupling hydrosilylation (Fig. 2b). Various maleimides with an aryl unit (1a-1w), whether it is electronwithdrawing or electron-donating, react efficiently with hydrosilane $2 \mathbf{a}$ to give desired products $(\mathbf{3 a}-\mathbf{3 w})$ in excellent enantioselectivities (93-99\% ees) and moderate to good yields (up to $99 \%$ yield). It should be noted that the coordination capacity of the $\mathrm{Pd}-\mathrm{L}$ complex with the activated alkene substrate possibly decreases due to the weakened solubility in the toluene and unexpected electronic properties of maleimides that with OR groups, resulting into a decreased yield of corresponding products, such as the representative examples of $\mathbf{3 d}$, $\mathbf{3 e}$, and $\mathbf{3 g}$. In addition, it was observed in experiments that the standard silica gel chromatography purification of the product led to the formation of succinimides 4 by silica gel promoted desilylation of the products. More specially, $N$-unsubstituted maleimide $\mathbf{1 x}$ is also tolerated, which is notable since a $\mathrm{NH}$ group can be proven to be no interference during undergoing $\mathrm{Si}-\mathrm{C}$ coupling hydrosilylation, albeit the enantioselectivity is slightly decreased as $81 \%$ ee with $69 \%$ yield. In addition, high efficiency and stereoselectivity was observed with $\mathrm{N}$-alkylmaleimides $(\mathbf{1 y}-\mathbf{1 b b})$. A substrate bearing an additional $\mathrm{N}$ - or Sheterocycle performed smoothly under the optimised reaction conditions to deliver the desired product (3cc or 3 dd with $84 \%$ yield and $96 \% e e$ ).

We subsequently examined the possibility of the catalytic asymmetric hydrosilylation for the remote control of axial chirality when the $\mathrm{N}$-arylmaleimide substrates bearing bulky group at ortho-position of aryl unit were used (Fig. 2c). The influence of bulky substitution on the aryl ring was investigated to probe the steric effect and it was found that the tert-butyl group with large $B$ values (about 15.5) ${ }^{58}$ guaranteed the perfect and remote control of axial chirality (for 3gg, 99\% ee with 99:1 d.r.). Notably, except 3gg, the atropisomers of mono-substituted $\mathrm{N}$ arylmaleimide-derived silyl products $\mathbf{3 e e}-\mathbf{3 h h}$ were co-existed in this protocol, which difficultly affords the pure and single atropisomer in the palladium-catalysed hydrosilylation. 
Table 1 Optimisation of reaction conditions ${ }^{a}$.

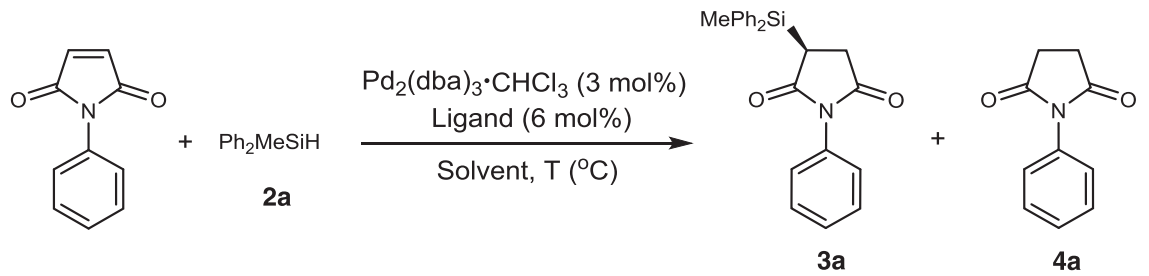

\begin{tabular}{|c|c|c|c|c|c|c|c|c|c|}
\hline Entry & Ligand & Conversion (\%) & $3 a / 4 a^{b}$ & $e e \%$ of $3 a^{c}$ & Entry & Ligand & Conversion (\%) & $3 a / 4 a^{b}$ & $e e \%$ of $3 a^{c}$ \\
\hline 1 & L1 & 97 & $25: 75$ & 70 & 14 & L14 & 14 & $<1: 99$ & ND \\
\hline 2 & L2 & 95 & $17: 83$ & 69 & 15 & L15 & $>99$ & $<1: 99$ & ND \\
\hline 3 & L3 & $>99$ & $30: 70$ & 68 & 16 & L16 & 28 & $<1: 99$ & ND \\
\hline 4 & L4 & $>99$ & $29: 71$ & 76 & 17 & L17 & 29 & $<1: 99$ & ND \\
\hline 5 & $\mathbf{L 5}$ & trace & ND & ND & 18 & L18 & $>99$ & $<1: 99$ & ND \\
\hline 6 & L6 & $>99$ & $8: 92$ & 62 & Entry & Solvent ${ }^{d}$ & Conversion (\%) & $3 a / 4 a^{b}$ & $e e \%$ of $3 a^{c}$ \\
\hline 7 & L7 & $>99$ & $59: 41$ & 79 & & & & & \\
\hline 8 & L8 & 93 & $50: 50$ & 79 & 19 & Dioxane & 99 & $67: 32$ & 92 \\
\hline 9 & L9 & $>99$ & $41: 59$ & 93 & $20^{e}$ & Toluene & $>99$ & $93: 7$ & 96 \\
\hline 10 & $\mathbf{L 1 0}$ & 90 & $4.5: 95.5$ & 91 & 21 & $\mathrm{Et}_{2} \mathrm{O}$ & $>99$ & $33: 67$ & 92 \\
\hline 11 & L11 & $>99$ & $4: 96$ & 86 & 22 & DCE & $>99$ & $85: 15$ & 94 \\
\hline 12 & L12 & $>99$ & $68: 32$ & 94 & 23 & $\mathrm{THF}$ & $>99$ & $4: 96$ & 70 \\
\hline 13 & L13 & 95 & $4: 96$ & 31 & 24 & DCM & $>99$ & $96: 4$ & 93 \\
\hline
\end{tabular}

The structure of chiral ligands in this work:<smiles></smiles>

L6, $\mathrm{Ar}=4-\mathrm{OMe}-\mathrm{Ph}$

$\mathrm{L7}, \mathrm{Ar}=4-\mathrm{CF}_{3}-\mathrm{Ph}$

$\mathrm{L8}, \mathrm{Ar}=3-\mathrm{CF}_{3}-\mathrm{Ph}$

L9, $\mathrm{Ar}=3,5-\mathrm{CF}_{3}-\mathrm{Ph}$

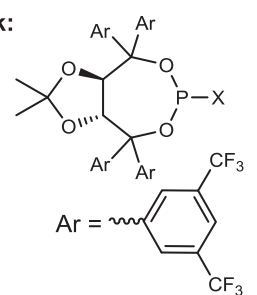<smiles>[R]c1ccc2ccccc2c1-c1c(P)ccc2ccccc12</smiles><smiles>CN(C)p1oc2ccc3ccccc3c2c2c(ccc3ccccc32)o1</smiles>

L14, R $=\mathrm{PPh}_{2}$

L1, $\mathrm{Ar}=4-\mathrm{Et}-\mathrm{Ph}$

L2, $\mathrm{Ar}=4{ }^{-} \mathrm{Pr}-\mathrm{Ph}$

$\mathrm{L} 3, \mathrm{Ar}={ }^{-}{ }^{\mathrm{t}} \mathrm{Bu}-\mathrm{Ph}$

$\mathrm{L4}, \mathrm{Ar}=4-\mathrm{TMS}-\mathrm{Ph}$<smiles>[Y9]C1([AlH2])OPOC([AlH2])([AlH2])C2OC(C)(C)O[C@H]21</smiles>

L10, $X=\mathrm{Ph}$<smiles>c1ccccc1</smiles>

L11, $X=\mathrm{NEt}_{2}$

$\mathrm{L5}, \mathrm{Ar}=4-\mathrm{F}-3,5-\mathrm{TMS}-\mathrm{Ph}$

L12, $X=$ Pyrrolidineyl

L13, $\mathrm{Ar}=\mathrm{C}_{6} \mathrm{~F}_{5}$

$\mathrm{L19}, \mathrm{Ar}=4-\mathrm{CF}_{3}-\mathrm{Ph}$<smiles>COc1ccc(P(=O)(O)c2ccccc2)c(-c2c([PH](=O)(=O)c3ccccc3)ccc3c2OCO3)c1</smiles><smiles></smiles>

L18

L17,(R)-DTBM-SEGPHOS

$\mathrm{Ar}=3,5-(t-\mathrm{Bu})_{2}-4-\mathrm{MeO}-\mathrm{C}_{6} \mathrm{H}_{2}$

aAll the reactions were run on a $0.1 \mathrm{mmol}$ scale in $1.0 \mathrm{~mL}$ DCE (entries 1-13) or toluene (entries 14-18) at $60^{\circ} \mathrm{C}$ for $18 \mathrm{~h}$.

bDetermined by $1 \mathrm{H}$ NMR using dibromomethane as an internal standard.

'Determined by chiral HPLC.

The reactions were performed with $\mathrm{Pd}_{2}(\mathrm{dba})_{3}$ and ligand $\mathrm{L} 12$.

${ }^{\mathrm{e}}$ The reaction temperature is $50^{\circ} \mathrm{C}$.

Remote control of axial chirality by palladium-catalysed hydrosilylation. To construct axially chiral $\mathrm{N}$-arylmaleimide derivatives via catalytic asymmetric hydrosilylation, we envisioned the introduction of two groups on the ortho-position of $\mathrm{N}$ arylmaleimides to stabilise the atropisomeric chirality during the remote control by palladium catalyst (Fig. 3a). Steric modification of one of the substituents on $3 \mathbf{h h}$ by an aryl group could counter racemisation at high temperature. Owing to unexpected effect of much bulky group on catalytic asymmetric hydrosilylation, the other concern was also that reductive side-products could form. Fortunately, no detrimental effects to the chemo- and stereoselectivity of this process were observed when biarylmaleimides were used (Fig. 3b), and all the atropisomeric succinimides $\mathbf{5 a}-\mathbf{5 z}$ bearing an additional $s p^{3}$-central chirality that with a high energy barrier for $\mathrm{C}-\mathrm{N}$ bond rotation (for example, the energy barrier for compound 5a is $44.2 \mathrm{kcal} / \mathrm{mol}$, see Supplementary Fig. 10) were obtained in moderate to high yields (up to $97 \%$ yield) and good enantioselectivities (up to $95 \%$ ee) as well as excellent diastereoselectivity (up to $>99: 1$ d.r.). An assortment of easily available $\mathrm{N}$-arylmaleimides was viable for this stereospecific $\mathrm{Si}-\mathrm{C}$ coupling hydrosilylation as well as remote control of axial chirality of $\mathrm{C}-\mathrm{N}$ bond. Expanding the substrate scope to investigate hydrosilanes permitted us to forge other arylsilanes for the catalytic asymmetric hydrosilylation. For example, the atropisomeric succinimides $\mathbf{5 v}-\mathbf{5 y}$ could be also achieved in excellent diastereo- and enantioselectivity (91-95\% ee and 97:3 to >99:1 d.r.). However, bulky arylsilane that containing $t$-Bu group on aromatic ring slowly reacted to form the desired atropisomeric succinimide $\mathbf{5 w}$ under the same reaction conditions, which revealed the steric repulsion between arylsilane and ortho-substituted $\mathrm{N}$-arylmaleimide is not inconsiderable. Lastly, a benzofuran-containing $\mathrm{N}$ arylmaleimide was also successfully $\mathrm{Si}-\mathrm{C}$ coupling to generate the desired silyl atropisomer in $87 \%$ yield and $95 \%$ ee. Notably, the absolute configuration of the atropisomeric succinimide $(P, S)-\mathbf{5 f}$ 
Identification of an effective chiral catalyst

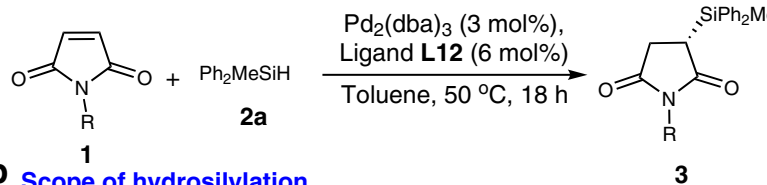

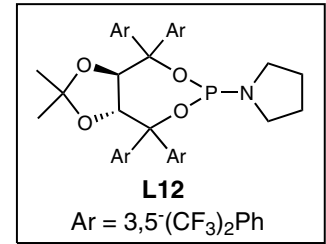

Scope of hydrosilylatio

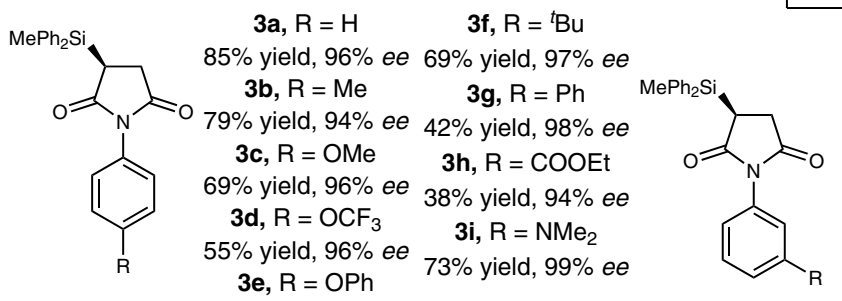

$3 \mathbf{j}, \mathrm{R}=\mathrm{Me}$

$87 \%$ yield, $96 \%$ ee

3k, $\mathrm{R}=\mathrm{F}$

$77 \%$ yield, $97 \%$ ee

3l, $\mathrm{R}=\mathrm{Cl}$

$72 \%$ yield, $97 \%$ ee

$3 \mathrm{~m}, \mathrm{R}=\mathrm{OMe}$

$72 \%$ yield, $95 \%$ ee

3n, $\mathrm{R}=\mathrm{CF}_{3}$<smiles></smiles>
$43 \%$ yield, $97 \%$ ee

$57 \%$ yield, $96 \%$ ee

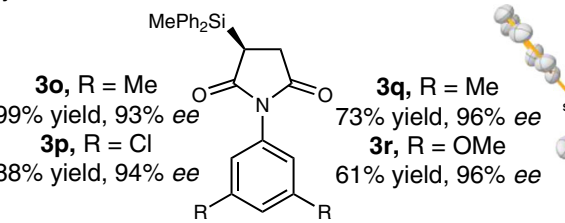<smiles>O=C1C[C@@H]([AsH2])C(=O)N1</smiles><smiles>[2H]c1cc(I)cc(F)c1P</smiles>
$74 \%$ yield, $96 \%$ ee

3t, $\mathrm{R}=\mathrm{OMe}$

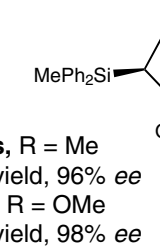<smiles>C=CCCC</smiles>
$1 \%$ yield, $96 \%$ ee

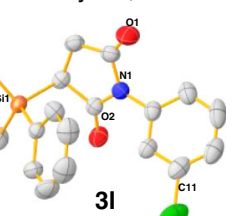<smiles></smiles>

$55 \%$ yield, $93 \%$ ee

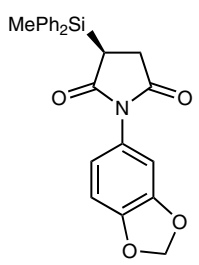

$3 w$ $68 \%$ yield, $93 \%$ ee

C<smiles>Cc1ccccc1N1C(=O)C[C@H](O)C1=O</smiles>

3ee<smiles>[107Os]</smiles>
$96 \%$ ee, d.r. $=58: 42$<smiles>O=C1C[C@H]([AsH2])[C@@H](O)C1=O</smiles>

groups

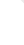

\section{te control of axial chirality}<smiles>COc1ccccc1N1C(=O)C[C@H](SCCN)C1=O</smiles>

3ff

$96 \%$ yield, $94 \%$ ee, d.r. $=59: 41$<smiles>CCCCS[C@@H]1CC(=O)N(c2ccccc2C(C)(C)C)C1=O</smiles>

$3 g g$

$75 \%$ yield,

$99 \%$ ee,

d.r. $=99: 1$<smiles>C[AsH3][C@@H]1CC(=O)N(N2CCCCC2)C1=O</smiles>
$84 \%$ yield, $96 \%$ ee

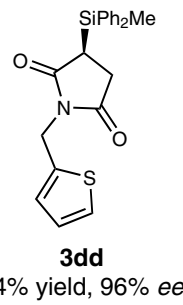

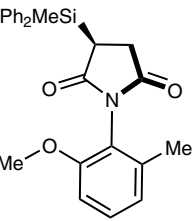

3hh

$59 \%$ yield

$93 \%$ ee,

d.r. $=78: 22$

Fig. 2 Enantioselective palladium-catalysed hydrosilylation of maleimides. a The determination of chiral palladium catalyst after screening of a variety of chiral ligands and reaction parameters, and that corresponding to $\mathbf{L 1 2}$ is optimal. $\mathbf{b}$ The catalytic asymmetric hydrosilylation of maleimides is broadly applicable, affording silyl products with excellent enantioselectivities (up to $99 \%$ ee). Products containing S-heterocycle and unsubstituted imide can be accessed. c The effect of bulky groups at the ortho-position of $\mathrm{N}$-arylmaleimides on enantioselective $\mathrm{Si}-\mathrm{C}$ coupling hydrosilylation with respect to the remote control of axial chirality.

was suitable for the determination of the remote control of axial chirality as $P$ through $\mathrm{X}$-ray crystallography analysis.

Downstream transformations of enantiomerically enriched silyl succinimides. To demonstrate the practicability of the catalytic asymmetric hydrosilylation, we carried out gram-scale reaction for the model transformation of 1a (Fig. 4a), which offered the same high enantiomeric excess (ee) compared with the small-scale process. Then, the enantiomerically enriched silyl succinimides can be converted to pyrrolidine and its derivatives, and the silyl group could be acted as a removable placeholder or masked auxiliary in these transformations. Synthesis of chiral $N$ aryl amino alcohol 7 under the Fleming-Tamao's oxidation conditions $^{59}$ showed the Si-linked $s p^{3}$ central chirality can be retained with high ee value $(96 \%$ ee). This transformation offers an attractive entry for synthesis of chiral amino alcohols that 
a Design of novel atropisomeric succinimides and identification of catalyst system

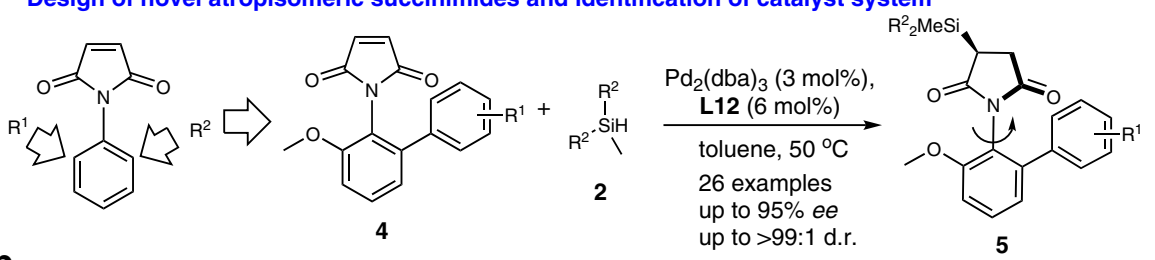

b scope of catalytic asymmetric hydrosilylation for the single-step construction of atropisomeric succinimides<smiles>CCCCC[C@H]1CC(=O)N(c2c(OC)cccc2-c2ccc(P)cc2)C1=O</smiles>

$5 a, R=H, 82 \%$ yield, $94 \%$ ee, d.r. $=95: 5$ $\mathbf{5 b}, \mathrm{R}=\mathrm{Me}, 85 \%$ yield, $92 \%$ ee, d.r. $=95: 5$ $5 c, \mathrm{R}=\mathrm{Cl}, 92 \%$ yield, $86 \%$ ee, d.r. $=94: 6$ $\mathbf{5 d}, \mathrm{R}=\mathrm{SMe}, 30 \%$ yield, $87 \%$ ee, d.r. $=81: 19$ $\mathbf{5 e}, \mathrm{R}=\mathrm{TMS}, 86 \%$ yield, $93 \%$ ee, d.r. $=97: 3$

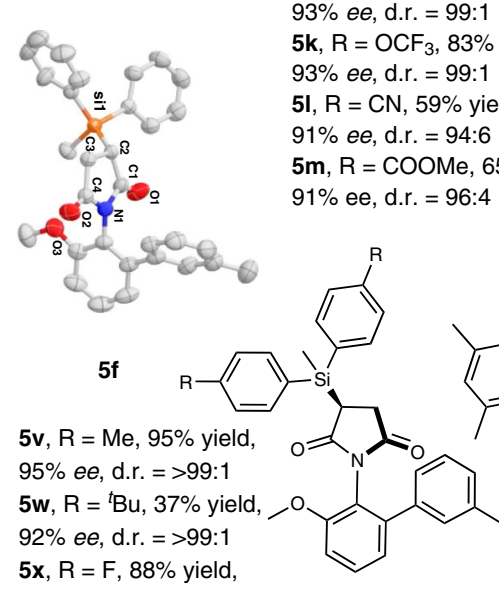<smiles>CCCCC[C@H]1CC(=O)N(c2c(OC)cccc2-c2cccc(P)c2)C1=O</smiles>

$\mathbf{5 f}, \mathrm{R}=\mathrm{Me}, 95 \%$ yield $94 \%$ ee, d.r. $=99: 1$ $\mathbf{5 g}, \mathrm{R}=\mathrm{F}, 92 \%$ yield, $94 \%$ ee, d.r. $=96: 4$ $\mathbf{5 h}, \mathrm{R}=\mathrm{Cl}, 81 \%$ yield, $95 \%$ ee, d.r. $=94: 6$ $5 \mathbf{i}, \mathrm{R}=\mathrm{OMe}, 68 \%$ yield, $93 \%$ ee, d.r. $=91: 9$ $5 \mathbf{j}, \mathrm{R}=\mathrm{CF}_{3}, 91 \%$ yield, $93 \%$ ee, d.r. $=99: 1$ $\mathbf{5 k}, \mathrm{R}=\mathrm{OCF}_{3}, 83 \%$ yield $93 \%$ ee, d.r. $=99: 1$ $5 \mathrm{I}, \mathrm{R}=\mathrm{CN}, 59 \%$ yield $91 \%$ ee, d.r. $=94: 6$ $5 \mathrm{~m}, \mathrm{R}=\mathrm{COOMe}, 65 \%$ yield,<smiles>CCCCCS[C@H]1CC(=O)N(c2c(OC)cccc2-c2cc(P)cc(P)c2)C1=O</smiles>

5n, $\mathrm{R}=\mathrm{Me}, 93 \%$ yield $93 \%$ ee, d.r. $=>99: 1$ 5o, $\mathrm{R}=\mathrm{Cl}, 93 \%$ yield, $93 \%$ ee, d.r. $=97: 3$ $5 p, \mathrm{R}=\mathrm{OMe}, 93 \%$ yield $92 \%$ ee, d.r. $=>99: 1$ $\mathbf{5 q}, \mathrm{R}=\mathrm{CF}_{3}, 91 \%$ yield, $91 \%$ ee, d.r. $=>99: 1$

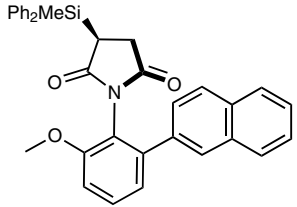

$5 \mathbf{r}, 60 \%$ yield, $89 \%$ ee, d.r. $=92: 8$ $\mathrm{Ph}_{2} \mathrm{MeSi}$

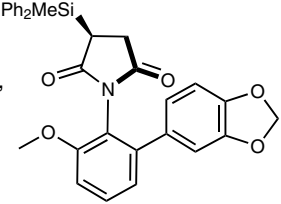

5s, $97 \%$ yield,

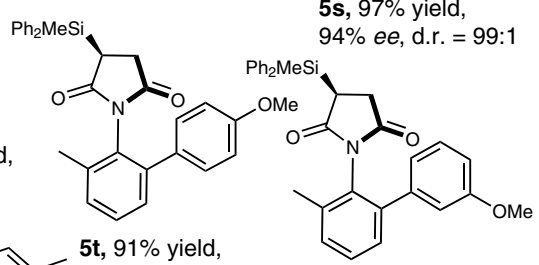

5t, $91 \%$ yield<smiles>COc1cccc(-c2cccc(C)c2)c1N1C(=O)CC([Si](c2cc(C)cc(C)c2)(c2cc(C)cc(C)c2)c2cccc([Se])c2)C1=O</smiles>

$5 y, 94 \%$ yield, $95 \%$ ee, d.r. $=>99: 1$
$5 \mathrm{u}, 90 \%$ yield, $93 \%$ ee, d.r. $=>99: 1$<smiles>CCCCCC[C@H]1CC(=O)N(c2c(OC)cccc2-c2cc3ccccc3o2)C1=O</smiles>

$5 z, 87 \%$ yield, $95 \%$ ee, d.r. $=92: 8$

Fig. 3 Remote control of axial chirality of $\mathbf{C}-\mathbf{N}$ bond by hydrosilylation. a The design of $\mathbf{C}-\mathbf{N}$ bond rotatable atropisomers by introduction of two different substituents on the ortho-position of $\mathrm{N}$-arylmaleimides to stabilise axial chirality. $\mathbf{b}$ The catalytic asymmetric hydrosilylation is broadly applicable in the construction of atropisomeric $\mathrm{N}$-arylmaleimides with good chemo-, diastereo-, and enantioselectivity and in up to $97 \%$ yield. Products containing sp 3 central chirality and axial chirality can be accessed in the single step of $\mathrm{Si}-\mathrm{C}$ coupling hydrosilylation.

could be used as precursors to biologically active molecules. In contrast, the oxidation of silyl succinimides 3 under the same reaction conditions, the desilylation product, 1-phenyl-pyrrolidine-2,5-dione, was formed exclusively. Recent progress on the radical cation-induced cyclisation of simple $\mathrm{N}$-arylpyrrolidine with iodonium ylides leading to a broad range of indoline derivatives ${ }^{60}$ inspired us to evaluate the placeholder effect of silyl group. And as already mentioned in this work, there is no catalytic asymmetric version for the enantioselective synthesis of indoline derivatives. Under the reported reaction conditions, the corresponding product $\mathbf{8}$, containing an additionally carbonstereogenic centre, was obtained in good enantioselectivity and promising diastereoselectivity (Fig. 4b). Unexpectedly, the more hindered ortho-position to the silyl group and amino group was the preferential cyclisation site, which is different from that of generally accepted pathway. The site-selective functionalisation was ascribed to the $\beta$-effect of silicon that featured with the hyperconjugation stabilisation of the cation intermediate by the $\mathrm{Si}-\mathrm{C} \sigma$-bond ${ }^{61}$. Recent reports revealed the powerful potential of photoredox catalysis in the functionalisation of $\mathrm{C}-\mathrm{H}$ bond ${ }^{62-65}$, which promote us to evaluate the chirality transfer of Si-linked carbon stereocenter on chiral silyl arylpyrrolidine to stereoselective photocatalysed $\mathrm{C}-\mathrm{H}$ functionalisation. We believed the chiral silyl group as a masked hydrogen or hydroxyl group plays important role in the silicon-mediated construction of carbonstereogenic centre during photoredox-catalysed $\mathrm{C}-\mathrm{H}$ functionalisation, providing supplementary method to build chiral molecules that it is a difficult and challenging task in photocatalytic reaction system ${ }^{66}$. Considered the importance of photocatalysed dual $\mathrm{C}-\mathrm{H}$ bond functionalisation (dehydrogenation/[2+2] cycloaddition) of pyrrolidine that reported by Xu et al. ${ }^{67}$, we checked the asymmetric version with chiral $N$-arylpyrrolidine $\mathbf{6}$ as starting material under the standard reaction conditions. The synthetic potential of this process can be supported by the perfect 
$\mathbf{a}_{\text {Gram-scale synthesis }}$

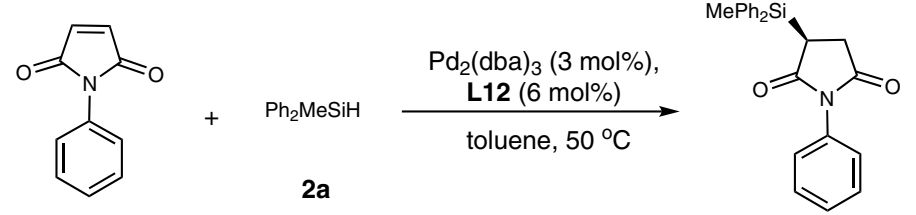

1a, $0.87 \mathrm{~g}, 5 \mathrm{mmol}$

3a, $1.37 \mathrm{~g}$,

$74 \%$ yield, $96 \%$ ee

b Reduction of carbonyl group and conversions to structurally diverse products

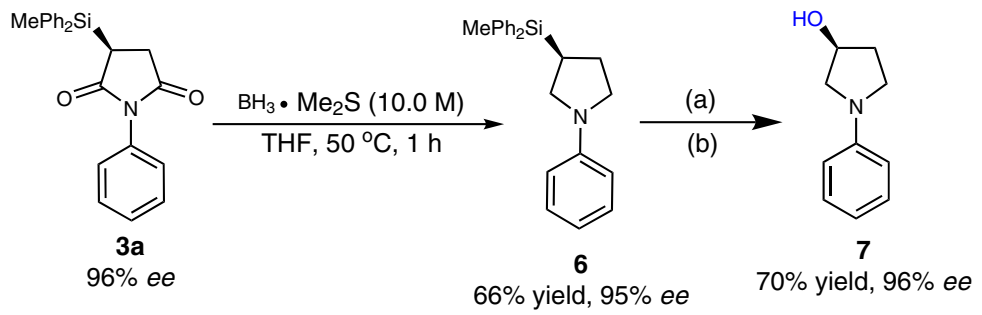

(c)

$\mathrm{CaH}_{2}(0.5 \mathrm{eq})$, $\mathrm{PhIC}(\mathrm{COOMe})_{2}(2 \mathrm{eq})$

$\mathrm{DCE}, 70^{\circ} \mathrm{C}, 20 \mathrm{~min}$

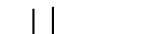

(a) $\mathrm{BF}_{3}-2 \mathrm{AcOH}(20$ eq)

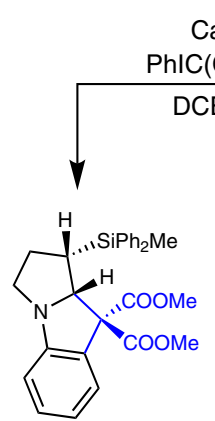

8, $40 \%$ yield, d.r. $=89: 11$

$97 \%$ ee (major isomer)

$96 \%$ ee (minor isomer)
$\mathrm{CHCl}_{3}, 65^{\circ} \mathrm{C}, 16 \mathrm{~h}$

(b) $\mathrm{KF}$ (4 eq), $\mathrm{KHCO}_{3}$ (4 eq),

$\mathrm{H}_{2} \mathrm{O}_{2}(30 \%$ aq, 23 eq)

$\mathrm{THF} / \mathrm{MeOH}=1: 1,65^{\circ} \mathrm{C}, 12 \mathrm{~h}$

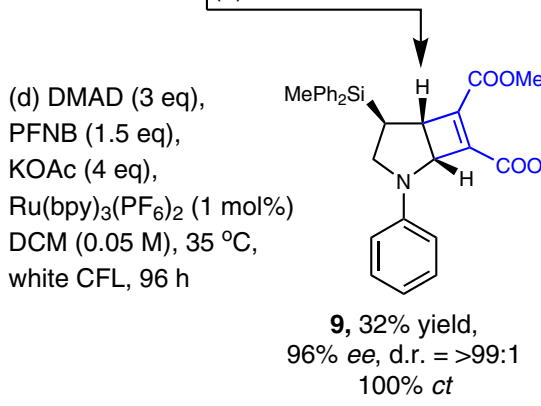

Fig. 4 Gram-sale synthesis and functionalisation and demonstration of utility. a Gram-scale reaction. Compared with the small-scale reaction, using substrates $\mathbf{1} \mathbf{a}$ and $\mathbf{2} \mathbf{a}$ in a gram-scale reaction produced the desired product $\mathbf{3} \mathbf{a}$ with the same level of enantiomeric excess (ee) and yield. $\mathbf{b}$ The silyl succinimides can be readily reduced to the stable silylpyrrolidine that could be transferred into structurally diverse and chiral $\mathrm{N}$-heterocycles without racemisation. DMAD dimethyl acetylenedicarboxylate, PFNB petafluoronitrobenzene, CFL compact fluorescent light, ct the value of chirality transfer.

chirality transfer $(100 \% c t)$ that product 9 was obtained in $>99: 1$ d.r. and $96 \%$ ee. Therefore, these experiments in Fig. 4b suggested that one emerging application of placeholder effect of silyl group is its use in the enantioselective functionalisation of $s p^{3} \mathrm{C}-\mathrm{H}$ bonds via silicon-mediated chirality transfer.

\section{Discussion}

To clarify the stereospecific Si-C coupling process by palladiumcatalysed hydrosilylation of maleimides, DFT calculations revealed that high chemo- and enantioselectivity originates from the aromatic interaction and steric repulsion caused by chiral TADDOL-derived phosphoramidite acting with the Pd-Si intermediate's aryl unit, in turn coordinated with carbon-carbon double bond of maleimide. In the more favourable pathway (path A of Supplementary Fig. 8) migratory insertion of an Pd/olefin hydride complex followed by reductive $\mathrm{Si}-\mathrm{C}$ coupling (simplified as Chalk-Harrod mechanism) ${ }^{68}$, 69 . Thus the Si-C coupling hydrosilylation but not olefin reduction occurred due to the irreversible $\beta$-hydride elimination that inhibited by the steric repulsion of chiral ligand. And the control experiments with deuterium labelling studies (KIE) determined the $\mathrm{Si}-\mathrm{H}$ action is a key step in this reaction (Supplementary Fig. 3), indicating that crucial role of bulky P-ligand bearing a large cavity in the directing migratory insertion of hydride to carbon-carbon double bond. The formation of $\mathrm{H}-\mathrm{Pd}-\mathrm{Si}$ intermediate within suitable cavity-type structure as a chiral proton shuttle arose from a TADDOL-derived phosphoramidite is necessary for the high enantioselectivity during the stereospecific migratory insertion of an olefin hydride complex, which could be supported by the ${ }^{31} \mathrm{P}$ NMR analysis, nonlinear effect, and DFT calculations (Supplementary Figs. 7, 8). In addition, the absolute configuration of the silyl products $\mathbf{3}$ or $\mathbf{5}$ mainly depends on the cavity size of the ligand, which is determined by the extension direction of the four aryl groups on TADDOL-derived phosphoramidite L12, especially two of them. And one of the aryl groups that regulated the steric hindrance is perpendicular to the maleimide substrate, in which a chiral wall as an external cavity surface can be formed to control the stereoselective direction of hydrosilylation of maleimide that is conducive to highly enantioselective addition via the option of less steric repulsion.

In summary, the stereospecific $\mathrm{Si}-\mathrm{C}$ coupling hydrosilylation of maleimides affords a series of silyl succinimides with the aid of stable and reactive Pd catalyst. Through the development of Pdcatalysed hydrosilylation, we achieved remote hydrosilylation 
-controlled construction of $\mathrm{C}-\mathrm{N}$ axial chirality within orthosubstituted $\mathrm{N}$-arylmaleimides. Owing to the compatibility of steric repulsion as well as electron-rich and electron-deficient substituents, this $\mathrm{Si}-\mathrm{C}$ coupling hydrosilylation reaction provides a way to diversify synthetically useful intermediates and complex molecules benefited from the concept of silicon-mediated organic synthesis.

\section{Methods}

General procedure for the palladium-catalysed hydrosilylation. A vial was charged with $N$-arylmaleimide $1(0.3 \mathrm{mmol}), \mathrm{Pd}_{2}(\mathrm{dba})_{3}(8.2 \mathrm{mg}, 3.0 \mathrm{~mol} \%),(R, R)-$ L12 (20.1 mg, 6 mol\%), and evacuated under high vacuum and backfilled with $\mathrm{N}_{2}$. Toluene $(3 \mathrm{~mL})$ was added subsequently. The mixture was stirred at $25^{\circ} \mathrm{C}$ for $10 \mathrm{~min}$, then the $\mathrm{Ph}_{2} \mathrm{MeSiH}(0.6 \mathrm{mmol})$ was added to the reaction. The mixture was stirred at $50^{\circ} \mathrm{C}$ in a preheated oil. Upon reaction completion, the mixture was filtered over a plug of silica gel (washed with $50 \mathrm{ml} \mathrm{EtOAc),} \mathrm{and} \mathrm{the} \mathrm{filtrate} \mathrm{was}$ concentrated. The crude was purified by column chromatography to give the corresponding product.

Full experimental details and the characterisation of compounds 3-8 are provided in the Supplementary Information.

\section{Data availability}

The X-ray crystallographic coordinates for structures reported in this study have been deposited at the Cambridge Crystallographic Data Centre (CCDC), under deposition numbers 1967248 and 1994220. These data can be obtained free of charge from The Cambridge Crystallographic Data Centre via www.ccdc.cam.ac.uk/data_request/cif. All the data generated and analysed in this study, including the experimental details, spectra for all unknown compounds, and computational modelling data associated with all of the tables and figures, see Supplementary Files. All data underlying the findings of this work are available from the corresponding author upon reasonable request. The source data underlying Supplementary Figs. 5-8 and 11 are provided as a Source Data file. Source data are provided with this paper.

Received: 27 January 2020; Accepted: 20 May 2020;

Published online: 09 June 2020

\section{References}

1. Park, S. B. $\left(\mathrm{C}_{6} \mathrm{~F}_{5}\right)_{3}$-catalyzed $\mathrm{sp}^{3} \mathrm{C}$-Si bond forming consecutive reactions. Chin. J. Chem. 37, 1057-1071 (2019).

2. Liu, D., Liu, B., Pan, Z., Li, J. \& Cui, C. Rare-earth metal catalysts for alkene hydrosilylation. Sci. China Chem. 62, 571-582 (2019).

3. Obligacion, J. V. \& Chirik, P. J. Earth-abundant transition metal catalysts for alkene hydrosilylation and hydroboration. Nat. Rev. Chem. 2, 15-34 (2018).

4. Du, X. \& Huang, Z. Advances in base-metal-catalyzed alkene hydrosilylation. ACS Catal. 7, 1227-1243 (2017).

5. Sun, J. \& Deng, L. Cobalt complex-catalyzed hydrosilylation of alkenes and alkynes. ACS Catal. 6, 290-300 (2016).

6. Cheng, C. \& Hartwig, J. F. Catalytic silylation of unactivated C-H bonds. Chem. Rev. 115, 8946-8975 (2015).

7. Min, G. K., Hernández, D. \& Skrydstrup, T. Efficient routes to carbon-silicon bond formation for the synthesis of silicon-containing peptides and azasilaheterocycles. Acc. Chem. Res. 46, 457-470 (2013).

8. Zaranek, M. \& Pawluc, P. Markovnikov hydrosilylation of alkenes: how an oddity becomes the goal. ACS Catal. 8, 9865-9876 (2018).

9. Wen, H., Liu, G. \& Huang, Z. Recent advances in tridentate iron and cobalt complexes for alkene and alkyne hydrofunctionalizations. Coord. Chem. Rev. 386, 138-153 (2019).

10. Garcia, L., Dinoi, C., Mahon, M. F., Maron, L. \& Hill, M. S. Magnesium hydride alkene insertion and catalytic hydrosilylation. Chem. Sci. 10, 8108-8118 (2019).

11. Yuan, W., Smirnov, P. \& Oestreich, M. Custom hydrosilane synthesis based on monosilane. Chem 4, 1443-1450 (2018).

12. Hu, M.-Y. et al. Ligands with 1,10-phenanthroline scaffold for highly regioselective iron-catalyzed alkene hydrosilylation. Nat. Commun. 9, p1-p11 (2018).

13. Tondreau, A. M. et al. Iron catalysts for selective anti-Markovnikov alkene hydrosilylation using tertiary silanes. Science 335, 567-570 (2012).

14. Chen, J., Guo, J. \& Lu, Z. Recent advances in hydrometallation of alkenes and alkynes via the first row transition metal catalysis. Chin. J. Chem. 36, 1075-1109 (2018).

15. Troegel, D. \& Stohrer, J. Recent advances and actual challenges in late transition metal catalyzed hydrosilylation of olefins from an industrial point of view. Coord. Chem. Rev. 255, 1440-1459 (2011).
16. Guo, J., Wang, H., Xing, S., Hong, X. \& Lu, Z. Cobalt-catalyzed asymmetric synthesis of gem-bis(silyl)alkanes by double hydrosilylation of aliphatic terminal alkynes. Chem 5, 1-15 (2019).

17. Guo, J., Shen, X. \& Lu, Z. Regio- and enantioselective cobalt-catalyzed sequential hydrosilylation/hydrogenation of terminal alkynes. Angew. Chem. Int. Ed. 56, 615-618 (2017).

18. Wen, H., Wan, X. \& Huang, Z. Asymmetric synthesis of silicon-stereogenic vinylhydrosilanes by cobalt-catalyzed regio-and enantioselective alkyne hydrosilylation with dihydrosilanes. Angew. Chem. Int. Ed. 57, 6319-6323 (2018).

19. Ramesh, R. \& Reddy, D. S. Quest for novel chemical entities through incorporation of silicon in drug scaffolds. J. Med. Chem. 61, 3779-3798 (2018).

20. Franz, A. K. \& Wilson, S. O. Organosilicon molecules with medicinal applications. J. Med. Chem. 56, 388-405 (2013).

21. Singh, S. \& Sieburth, S. M. Serine protease inhibition by a silanediol peptidomimetic. Org. Lett. 14, 4422-4425 (2012).

22. Huang, M.-Y., Yang, J.-M., Zhao, Y.-T. \& Zhu, S.-F. Rhodium-catalyzed Si-H bond insertion reactions using functionalized alkynes as carbene precursors. ACS Catal. 9, 5353-5357 (2019).

23. Wen, H., Wang, K., Zhang, Y., Liu, G. \& Huang, Z. Cobalt-catalyzed regio-and enantioselective Markovnikov 1,2-hydrosilylation of conjugated dienes. ACS Catal. 9, 1612-1618 (2019).

24. Zhan, G. et al. Enantioselective construction of silicon-stereogenic silanes by scandium-catalyzed intermolecular alkene hydrosilylation. Angew. Chem. Int. Ed. 57, 12342-12346 (2018)

25. Cheng, B., Liu, W. \& Lu, Z. Iron-catalyzed highly enantioselective hydrosilylation of unactivated terminal alkenes. J. Am. Chem. Soc. 140, 5014-5017 (2018).

26. Gribbler, M. W., Pirnot, M. T., Bandar, J. S., Liu, R. Y. \& Buchwald, S. L. Asymmetric copper hydride-catalyzed Markovnikov hydrosilylation of vinylarenes and vinyl heterocycles. J. Am. Chem. Soc. 139, 2192-2195 (2017).

27. Cheng, B., Lu, P., Zhang, H., Cheng, X. \& Lu, Z. Highly enantioselective cobalt-catalyzed hydrosilylation of alkenes. J. Am. Chem. Soc. 139, 9439-9442 (2017).

28. Miller, Z. D., Dorel, R. \& Montgomery, J. Regiodivergent and stereoselective hydrosilylation of 1,3-disubstituted allenes. Angew. Chem. Int. Ed. 54, 9088-9091 (2015).

29. Cheng, Z. et al. Highly regioselective sequential 1,1-dihydrosilylation of terminal aliphatic alkynes with primary silanes. Chin. J. Chem. 37, 457-461 (2019).

30. Oestreich, M. \& Rendler, S. "True" chirality transfer from silicon to carbon: asymmetric amplification in a reagent- controlled palladium-catalyzed hydrosilylation. Angew. Chem. Int. Ed. 44, 1661-1664 (2005).

31. Rendler, S., Oestreich, M., Butts, C. P. \& Lloyd-Jones, G. C. Intermolecular chirality transfer from silicon to carbon: interrogation of the two-silicon cycle for Pd-catalyzed hydrosilylation by stereoisotopochemical crossover. J. Am. Chem. Soc. 129, 502-503 (2007).

32. Sumida, Y., Yorimitsu, H. \& Oshima, K. Palladium-catalyzed preparation of silyl enolates from $\alpha, \beta$-unsaturated ketones or cyclopropyl ketones with hydrosilanes. J. Org. Chem. 74, 7986-7989 (2009).

33. Benohoud, M., Tuokko, S. \& Pihko, P. M. Stereoselective hydrosilylation of enals and enones catalysed by palladium nanoparticles. Chem. Eur. J. 17, 8404-8413 (2011).

34. Gandhamsetty, N. et al. Chemoselective silylative reduction of conjugated nitriles under metal-free catalytic conditions: $\beta$-silyl amines and enamines. Angew. Chem. Int. Ed. 54, 6832-6836 (2015).

35. Kim, Y. \& Chang, S. Borane-catalyzed reductive a-silylation of conjugated esters and amides leaving carbonyl groups intact. Angew. Chem. Int. Ed. 55, 218-222 (2016).

36. Pindwal, A. et al. Cerium-catalyzed hydrosilylation of acrylates to give a-silyl esters. Angew. Chem. Int. Ed. 56, 628-631 (2017).

37. Kim, E., Park, S. \& Chang, S. Silylative reductive amination of $\alpha, \beta$-unsaturated aldehydes: a convenient synthetic route to $\beta$-silylated secondary amines. Chem. Eur. J. 24, 5765-5769 (2018).

38. Ravasco, J. M., Faustino, H., Trindade, A. \& Gois, P. M. P. Bioconjugation with maleimides: a useful tool for chemical biology. Chem. Eur. J. 25, 43-59 (2019).

39. Oz, Y. \& Sanya, A. The taming of the maleimide: fabrication of maleimidecontaining 'clickable' polymeric materials. Chem. Rec. 18, 570-586 (2018).

40. Li, F., Li, X., Wang, Y. \& Zhang, X. Trismaleimide dendrimers: helix-tosuperhelix supramolecular transition accompanied by white-light emission. Angew. Chem. Int. Ed. 58, 17994-18002 (2019).

41. St. Amant, A. H. et al. A Diene-Containing Noncanonical Amino Acid Enables Dual Functionality in proteins: rapid diels-alder reaction with maleimide or proximity-based dimerization. Angew. Chem. Int. Ed. 58, $8489-8493$ (2019). 
42. Szijj, P. A., Bahou, C. \& Chudasama, V. Minireview: addressing the retromichael instability of maleimide bioconjugates. Drug Discov. Today 30, 28-34 (2018).

43. Marciniec, B. Hydrosilylation-A Comprehensive Review on Recent Advances. (Springer, Netherlands, 2009).

44. Nakajima, Y. \& Shimada, S. Hydrosilylation reaction of olefins: recent advances and perspectives. RSC Adv. 5, 20603-20616 (2015).

45. Uozumi, Y. \& Hayashi, T. Catalytic asymmetric synthesis of optically active 2alkanols via hydrosilylation of 1-alkenes with a chiral monophosphinepalladium catalyst. J. Am. Chem. Soc. 113, 9887-9888 (1991).

46. Hayashi, T. Axially chiral monophosphine ligands (MOPs) and their use for palladium-catalyzed asymmetric hydrosilylation of olefins. Cat. Today 62 3-15 (2000).

47. Gibsona, S. E. \& Rudda, M. The role of secondary interactions in the asymmetric palladium-catalysed hydrosilylation of olefins with monophosphane ligands. Adv. Synth. Catal. 349, 781-795 (2007).

48. Kumarasamy, E., Raghunathan, R., Sibi, M. P. \& Sivaguru, J. Nonbiaryl and heterobiaryl atropisomers: molecular templates with promise for atropselective chemical transformations. Chem. Rev. 115, 11239-11300 (2015).

49. Zhang, L. et al. Phosphoric acid-catalyzed atroposelective construction of axially chiral arylpyrroles. Nat. Commun. 10, 566 (2019).

50. Iorio, N. D. et al. Remote control of axial chirality: aminocatalytic desymmetrization of $\mathrm{N}$-arylmaleimides via Vinylogous Michael addition. J. Am. Chem. Soc. 136, 10250-10253 (2014).

51. Duan, W.-L., Imazaki, Y., Shintani, R. \& Hayashi, T. Asymmetric construction of chiral C-N axes through rhodium-catalyzed 1,4-addition. Tetrahedron 63, 8529-8536 (2007).

52. Iorio, N. D. et al. Targeting remote axial chirality control of N-(2-tertbutylphenyl) succinimides by means of Michael addition type reactions. Tetrahedron 72, 5191-5201 (2016)

53. Iorio, N. D. et al. Michael addition of oxindoles to N-(2-tert-Butylphenyl) maleimides: efficient desymmetrization for the synthesis of atropisomeric succinimides with quaternary and tertiary stereocenters. Synlett 49, 1519-1530 (2017).

54. Kumarasamy, E., Raghunathan, R., Jockusch, S., Ugrinov, A. \& Sivaguru, J. Tailoring atropisomeric maleimides for stereospecific [2+2] photocycloaddition photochemical and photophysical investigations leading to visible-light photocatalysis. J. Am. Chem. Soc. 136, 8729-8737 (2014).

55. Raghunathan, R., Kumarasamy, E., Jockusch, S., Ugrinova, A. \& Sivaguru, J. Engaging electronic effects for atropselective [5+2]-photocycloaddition of maleimides. Chem. Commun. 52, 8305-8308 (2016).

56. Liu, H.-C., Tao, H.-Y., Cong, H. \& Wang, C.-J. Silver(I)-catalyzed atroposelective desymmetrization of $\mathrm{N}$-arylmaleimide via 1,3-dipolar cycloaddition of azomethine ylides: access to octahydropyrrolo[3,4-c]pyrrole derivatives. J. Org. Chem. 81, 3752-3760 (2016).

57. Eudier, F., Righi, P., Mazzanti, A., Ciogli, A. \& Bencivenni, G. Organocatalytic atroposelective formal Diels-Alder desymmetrization of $\mathrm{N}$-arylmaleimides. Org. Lett. 17, 1728-173 (2015).

58. Ruzziconi, R., Spizzichino, S., Lunazzi, L., Mazzanti, A. \& Schlosser, M. B Values as a Sensitive Measure of Steric Effects. Chem. Eur. J. 15, 2645-2652 (2009).

59. Shin, K., Joung, S., Kim, Y. \& Chang, S. Selective synthesis of silacycles by borane-catalyzed domino hydrosilylation of proximal unsaturated bonds: tunable approach to 1,n-diols. Adv. Synth. Catal. 359, 3428-3436 (2017).

60. Zhao, Z. et al. Direct cyclization of tertiary aryl amines with iodonium ylides. Angew. Chem. Int. Ed. 57, 3792-3796 (2018).

61. Dichiarante, V. et al. The $\beta$ effect of silicon in phenyl cations. J. Am. Chem. Soc. 129, 15919-15926 (2007).

62. Johnston, C. P., Smith, R. T., Allmendinger, S. \& MacMillan, D. W. C. Metallaphotoredox-catalysed $\mathrm{sp}^{3}-\mathrm{sp}^{3}$ cross coupling of carboxylic acids with alkyl halides. Nature 536, 322-325 (2016).

63. Chu, J. C. K. \& Rovis, T. Amide-directed photoredox-catalysed C-C bond formation at unactivated $\mathrm{sp}^{3} \mathrm{C}-\mathrm{H}$ bonds. Nature 539, 272-275 (2016).

64. Liang, Y., Zhang, X. \& MacMillan, D. W. C. Decarboxylative $\mathrm{sp}^{3} \mathrm{C}-\mathrm{N}$ coupling via dual copper and photoredox catalysis. Nature 559, 83-88 (2018).
65. Perry, I. B. et al. Direct arylation of strong aliphatic C-H bonds. Nature $\mathbf{5 6 0}$, 70-75 (2018).

66. Litman, Z. C., Wang, Y., Zhao, H. \& Hartwig, J. F. Cooperative asymmetric reactions combining photocatalysis and enzymatic catalysis. Nature $\mathbf{5 6 0}$, 355-359 (2018).

67. $\mathrm{Xu}, \mathrm{G}$.-Q. et al. Dual C( $\left.\mathrm{sp}^{3}\right)-\mathrm{H}$ bond functionalization of $\mathrm{N}$-heterocycles through sequential visible-light photocatalyzed dehydrogenation/[2+2] cycloaddition reactions. Angew. Chem. Int. Ed. 57, 5110-5114 (2018).

68. Chalk, A. J. \& Harrod, J. F. Homogeneous catalysis. II. the mechanism of the hydrosilation of olefins catalyzed by group VIII metal complexes. J. Am. Chem. Soc. 87, 16-21 (1965).

69. LaPointe, A. M., Rix, F. C. \& Brookhart, M. Mechanistic studies of palladium (II)-catalyzed hydrosilylation and dehydrogenative silation reactions. J. Am. Chem. Soc. 119, 906-917 (1997).

\section{Acknowledgements}

This work was supported by the grants of National Natural Science Foundation of China (NSFC Nos. 21773051, 21703051, and 21901056), and Zhejiang Provincial Natural Science Foundation of China (LZ18B020001, LQ 19B040001, and LY18B020013). The authors thank K.Z. Jiang and X.Q. Xiao for their assistance on the MS and X-ray crystallographic analysis.

\section{Author contributions}

L.-W.X. conceived the concept. X.-W.G., Y.-L.S, J.-L.X., and X.-B.W carried out experiments, including the preparation of chiral ligands and the palladium-catalysed hydrosilylation. Y.-L.S. repeated the reaction results and carried out the X-ray crystallographic analysis of $\mathbf{5 f}$. X.-W.G. and Z.X. carried out the DFT calculations. G.-W.Y., L.L., and K.-F.Y. synthesised the substrates and conducted the structural analysis of new compounds. L.-W.X wrote the manuscript and all authors discussed the results and participated in revising the manuscript. L.-W.X. supervised the project.

\section{Competing interests}

The authors declare no competing interests.

\section{Additional information}

Supplementary information is available for this paper at https://doi.org/10.1038/s41467 020-16716-5.

Correspondence and requests for materials should be addressed to L.-W.X.

Peer review information Nature Communications thanks Hailong Yan and the other, anonymous, reviewer(s) for their contribution to the peer review of this work. Peer reviewer reports are available.

Reprints and permission information is available at http://www.nature.com/reprints

Publisher's note Springer Nature remains neutral with regard to jurisdictional claims in published maps and institutional affiliations.

Open Access This article is licensed under a Creative Commons Attribution 4.0 International License, which permits use, sharing, adaptation, distribution and reproduction in any medium or format, as long as you give appropriate credit to the original author(s) and the source, provide a link to the Creative Commons license, and indicate if changes were made. The images or other third party material in this article are included in the article's Creative Commons license, unless indicated otherwise in a credit line to the material. If material is not included in the article's Creative Commons license and your intended use is not permitted by statutory regulation or exceeds the permitted use, you will need to obtain permission directly from the copyright holder. To view a copy of this license, visit http://creativecommons.org/ licenses/by/4.0/.

(C) The Author(s) 2020 